\title{
Ressuscitação no trauma
}

\section{Trauma resuscitation}

\author{
Ana Paula de Carvalho Panzeri Carlotti
}

\begin{abstract}
RESUMO
Este texto aborda a avaliação inicial e o manejo sistematizado da criança vítima de trauma, assim como as particularidades da ressuscitação no trauma crânio-encefálico.
\end{abstract}

Palavras-chave: Traumatismo Múltiplo. Avaliação Primária. Avaliação Secundária. Lesões Crânio-encefálicas.

\section{Introdução}

O trauma é causa importante de morbi-mortalidade em crianças e adolescentes no mundo todo. No Brasil, na faixa de 1 a 19 anos, a mortalidade proporcional por causas externas foi de $56 \%$ em 2002, sendo o trauma responsável por mais de $50 \%$ destes óbitos. ${ }^{1}$

A ressuscitação da criança vítima de trauma deve começar rapidamente, de preferência, na cena do acidente. Os princípios da ressuscitação no trauma são os mesmos aplicados em outras situações de emergência e consistem no suporte precoce e efetivo das vias aéreas, ventilação e oxigenação, e na restauração da perfusão. A avaliação primária, realizada nos minutos iniciais do atendimento, visa identificar e tratar as lesões que podem levar o indivíduo à morte, e consiste na avaliação cardiopulmonar inicial e na estabilização do paciente. Esta avaliação é também chamada de abordagem "ABCDE" e envolve os seguintes passos: Avaliação rápida e estabilização da via aérea (Airway), respiração (Breathing), circulação
(Circulation), avaliação da condição neurológica (Disability), e exposição da pele à procura de lesões e manutenção da normotermia (Exposure and Enviromental control). A avaliação secundária deve ser realizada após a estabilização inicial do paciente, e inclui a história dirigida, o exame físico detalhado "da cabeça aos pés" e o estabelecimento de prioridades para o tratamento definitivo. ${ }^{2}$

\section{Avaliação inicial}

\section{Via aérea e respiração ("Airway"e “Breathing")}

Inicialmente, a prioridade no manejo da criança vítima de trauma é assegurar uma via aérea patente. Em virtude do risco de lesão da coluna cervical, especialmente em crianças submetidas a movimentos de aceleração e desaceleração, como em acidentes com veículos e quedas de altura, a via aérea da criança vítima de trauma deve ser aberta pela manobra de elevação da mandíbula com estabilização manual simultânea da coluna cervical (Figura 1). ${ }^{2}$ 


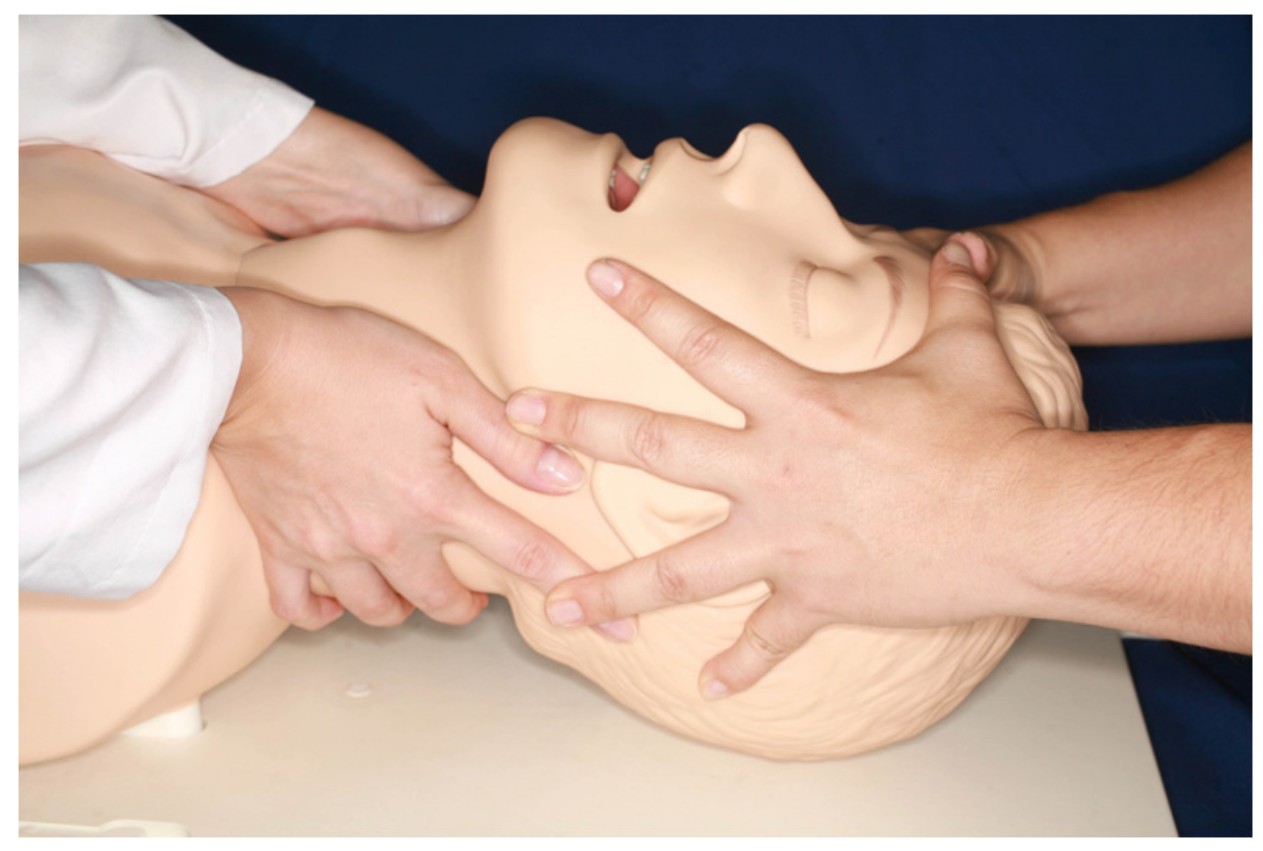

Figura 1: Abertura das vias aéreas pela elevação da mandíbula com estabilização simultânea da coluna cervical.

A manobra de inclinação da cabeça com elevação do queixo para abertura das vias aéreas é contraindicada em vítimas de trauma com possível lesão da cabeça ou do pescoço, pois pode piorar lesão préexistente na medula espinhal. Além disso, a cabeça e o pescoço devem ser seguros firmemente em posição neutra para prevenir movimentação do pescoço, devendo-se evitar tração do pescoço. Se dois socorristas estiverem presentes, o primeiro socorrista abre a via aérea com elevação da mandíbula enquanto o segundo assegura a estabilização da cabeça e do pescoço em posição neutra. Frequentemente, o occipício proeminente da criança causa leve flexão do pescoço quando ela é colocada em superfície plana. Para facilitar a manutenção da posição neutra, pranchas pediátricas com orifício para a cabeça podem ser utilizadas. Caso não haja disponibilidade deste tipo de prancha, um lençol dobrado deve ser colocado sob o dorso da criança a fim de elevá-lo aproximadamente $2 \mathrm{~cm}$, permitindo que a cabeça assuma posição neutra. Após abertura efetiva da via aérea com estabilização simultânea da coluna cervical, deve-se colocar colar cervical semirrígido, ajustado de modo a impedir flexão ou hiperextensão do pescoço. Caso a permeabilidade da via aérea esteja comprometida pela presença de corpo estranho (sangue, muco, fragmentos de dentes) ou regurgitação de conteúdo gástrico, pode-se utilizar um dispositivo de sucção rígido e de grosso calibre, como a sonda Yankauer, para desobstruir a via aérea. Ocasionalmente, pode ser necessária a retirada do corpo estranho com o fórceps pediátrico de Magill. ${ }^{2,3}$

As lesões de coluna cervical são menos frequentes em crianças do que em adultos vítimas de trauma. Entretanto, por possuírem ligamentos mais frágeis e musculatura menos desenvolvida em comparação aos adultos, as crianças podem apresentar lesão medular na ausência de fratura. Esta situação, chamada de síndrome da lesão medular sem anormalidade radiográfica (SCIWORA - "Spinal cord injury without radiographic abnormality"), associa-se a mau desfecho neurológico e é responsável por grande número de óbitos pré-hospitalares. Como este tipo de lesão, por definição, não pode ser excluído pela radiografia, todas as precauções devem ser tomadas a fim de se evitar piora potencial da lesão durante a fase de controle e manejo das vias aéreas. Portanto, deve-se imobilizar a coluna cervical de todas as crianças politraumatizadas na cena do acidente, mantendo-a imobilizada durante o transporte e a estabilização no serviço de referência. ${ }^{2}$

Inicialmente, deve-se administrar oxigênio a $100 \%$ a todas as vítimas de trauma por meio de dispositivos de alto fluxo (máscara não-reinalante). A intubação traqueal está indicada se houver comprometi- 
mento das vias aéreas em decorrência do trauma ou de obstrução, sinais de desconforto respiratório ou diminuição do nível de consciência com esforço respiratório inadequado e perda dos reflexos de proteção das vias aéreas. A intubação deve ser realizada preferencialmente pela via orotraqueal, com imobilização simultânea da coluna cervical (Figura 2). ${ }^{2,3}$

A pressão sobre a cartilagem cricoide (manobra de Sellick) pode ser útil para facilitar a intubação, particularmente nas situações em que se deve evitar a movimentação do pescoço. A intubação nasotraqueal deve ser evitada, pois requer maior manipulação da coluna cervical, além de ser contraindicada em crianças com fratura de base de crânio ou lesão maxilofacial, pelo risco de migração intracraniana do tubo traqueal. Em crianças com lesões traumáticas de vias aéreas, a intubação com dispositivos de fibra óptica ou o estabelecimento cirúrgico da via aérea podem ser necessários. Nestes casos, enquanto se aguarda por equipamento ou profissional especializado, uma máscara laríngea pode ser útil. Após a intubação, devese manter a coluna cervical imobilizada pelo uso do colar cervical. ${ }^{2,3}$

O objetivo do suporte ventilatório de vítimas de trauma é o restabelecimento e a manutenção de oxigenação e ventilação adequadas. A função respiratória deve ser avaliada, procurando-se estar alerta aos sinais de lesões intratorácicas, mesmo na ausência de sinais externos de trauma torácico, pois, como possui parede torácica bastante complacente, a criança pode ter lesões intratorácicas graves na ausência de fratura de costela ou sinais externos de lesão. Deve-se suspeitar de lesões torácicas se a criança tiver história de trauma torácico ou da região superior do abdome, arritmias cardíacas ou se houver dificuldade de fornecer ventilação efetiva à criança. São lesões intratorácicas graves potencialmente fatais o pneumotórax hipertensivo, o hemotórax, as feridas torácicas abertas, o tórax instável e o tamponamento cardíaco.

O pneumotórax hipertensivo pode resultar de trauma torácico fechado ou penetrante. $\mathrm{O}$ acúmulo de ar no espaço pleural causa colapso dos pulmões e compressão do coração e dos grandes vasos. $\mathrm{O}$ aumento progressivo da pressão intratorácica causa desconforto respiratório e deterioração da perfusão sistêmica em decorrência do desvio do mediastino para o lado contralateral, que obstrui o retorno venoso para o coração, ocasionando falência cardiovascular. Outros sinais clínicos de pneumotórax hipertensivo incluem hiperressonância à percussão, diminuição da expansibilidade torácica e diminuição ou ausência do murmúrio vesicular no lado acometido. Além disso, a criança pode apresentar distensão das veias do pescoço e desvio contralateral da traqueia, mas estes sinais são menos frequentes em crianças do que em adultos. O diagnóstico do pneumotórax hipertensivo

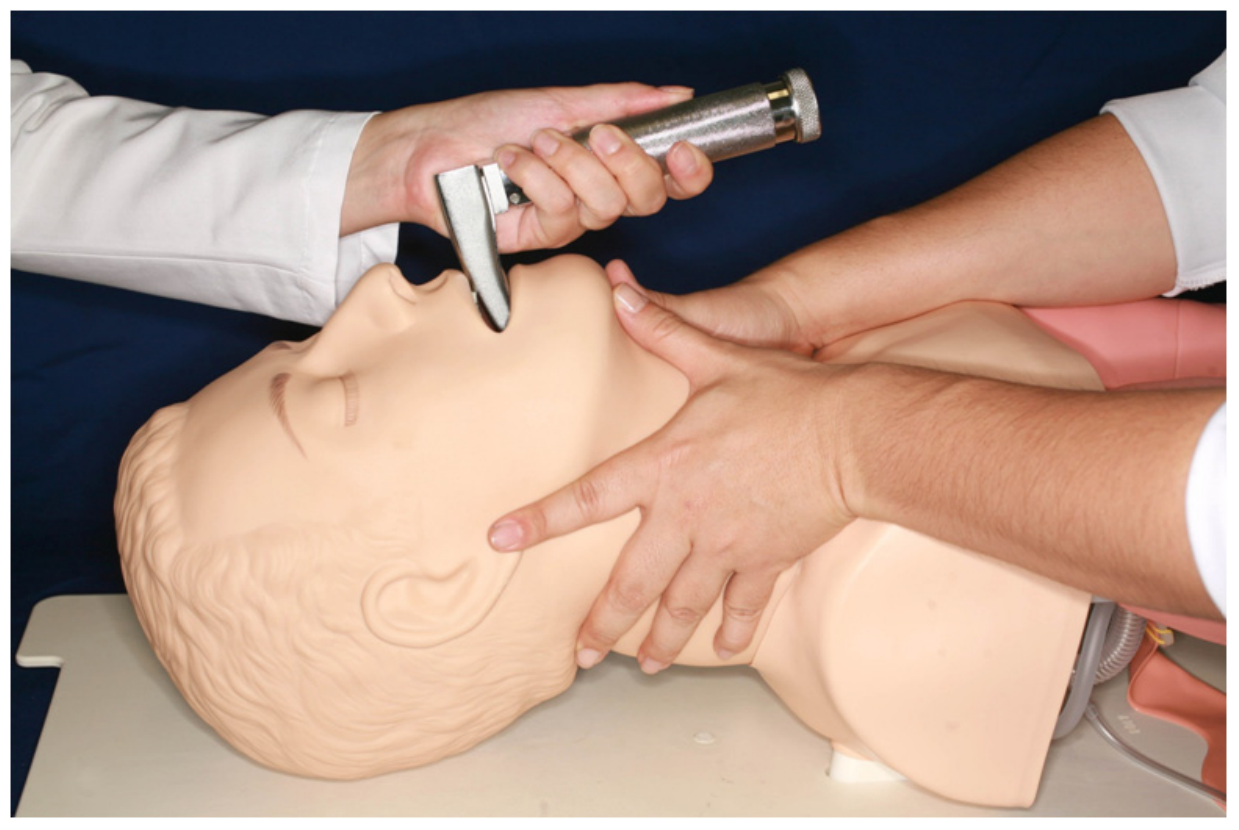

Figura 2: Intubação orotraqueal com imobilização manual simultânea da coluna cervical. 
deve ser feito com base em dados clínicos, devendose realizar o tratamento imediato, mesmo na ausência da radiografia de tórax confirmatória. O tratamento de emergência do pneumotórax hipertensivo consiste em descompressão por agulha seguida de drenagem torácica. A descompressão por agulha é feita inserindo uma agulha conectada a uma seringa contendo 5 $\mathrm{mL}$ de soro fisiológico no segundo espaço intercostal na linha hemiclavicular na borda superior da terceira costela. A agulha deve ser inserida em ângulo de $90^{\circ}$, aspirando concomitantemente com a seringa até a saída de ar. A seguir, desconecta-se a seringa, deixando a agulha aberta para o ar, o que permite que a pressão intratorácica se iguale à pressão atmosférica, aliviando a hipertensão. Ressalta-se que a simples descompressão do pneumotórax hipertensivo por agulha pode promover alívio imediato do desconforto respiratório e estabilização do quadro hemodinâmico.

O tórax instável resulta de fraturas múltiplas de costelas adjacentes, que causam instabilidade de uma porção da parede torácica. Esta instabilidade pode resultar em insuficiência respiratória e necessidade de ventilação com pressão positiva. Caso o paciente apresente também pneumotórax ou hemotórax, pode ser necessária a inserção de um dreno torácico. O manejo inicial das lesões torácicas graves potencialmente fatais se encontra na Tabela 1.

Após assegurar a permeabilidade da via aérea e a adequação da oxigenação e da ventilação, recomenda-se inserir uma sonda naso ou orogástrica para prevenir ou aliviar a distensão gástrica. Em pacientes com trauma maxilofacial ou suspeita de fratura de base de crânio, a sonda deve ser inserida pela via orogástrica para evitar migração intracraniana do tubo. ${ }^{2}$

\section{Circulação ("Circulation")}

O suporte circulatório da vítima de trauma inclui avaliação rápida da perfusão sistêmica, estabelecimento do acesso vascular, tratamento do choque hemorrágico e controle da hemorragia. O tipo mais comum de choque no politraumatizado é o hipovolêmico, cuja apresentação clínica se caracteriza por taquicardia, taquipneia, diminuição da pressão de pulso com pulsos finos, tempo de enchimento capilar prolongado, extremidades frias e alteração do estado mental. A hipotensão é usualmente manifestação tardia e ocorre quando há perda de mais do que $25 \%$ a $30 \%$ da volemia. Raramente, observa-se choque neurogênico associado à lesão grave do cérebro e do tronco cerebral, que se caracteriza por hipotensão com extremidades aquecidas, alargamento da pressão de pulso secundária à perda do tônus vascular e bradicardia causada por atividade simpática deficiente.

$\mathrm{O}$ acesso vascular deve ser estabelecido rapidamente. A primeira escolha é a punção de veia periférica - de preferência, duas veias calibrosas, com cateteres curtos e grossos (tipo "abocath"). Caso o acesso venoso periférico não seja obtido prontamente em poucos minutos, a via intraóssea deve ser estabelecida. Em pacientes com sinais de choque deve-se inicialmente administrar bolus de cristaloide (soro fisiológico a $0,9 \%$ ou Ringer lactato), $20 \mathrm{~mL} / \mathrm{kg}$ em 5 a 20 minutos. Se não houver melhora da perfusão sistêmica, um segundo bolus de cristaloide de $20 \mathrm{~mL} / \mathrm{kg}$ deve ser administrado rapidamente (em 5-20 minutos). Se houver persistência dos sinais de choque após a administração de 40-60 mL/kg de cristaloide, devese transfundir 10-15 mL/kg de concentrado de hemá-

\section{Tabela 1}

Manejo inicial das lesões torácicas potencialmente fatais

\begin{tabular}{ll}
\hline Lesão & Manejo inicial \\
\hline Pneumotórax hipertensivo & "ABC", descompressão rápida do espaço pleural com agulha e drenagem torácica. \\
Hemotórax & "ABC", descompressão do espaço pleural, drenagem torácica, bolus de fluido. \\
Tórax instável & "ABC", ventilação com pressão positiva, drenagem torácica em casos com pneumotórax \\
& ou hemotórax associado. \\
Tamponamento cardíaco & "ABC", drenagem pericárdica, bolus de fluido. \\
Pneumotórax aberto & "ABC", curativo oclusivo sobre a ferida torácica, descompressão do espaço pleural e \\
\hline
\end{tabular}


cias. Imediatamente após a chegada da criança na sala de emergência, deve-se obter uma amostra de sangue para exame de tipo sanguíneo e contraprova. Caso o sangue do mesmo tipo da criança não esteja disponível, pode-se administrar sangue tipo O-negativo. Lembrar que grandes volumes de transfusão podem resultar em hipocalcemia, devendo-se estar atento às concentrações séricas de cálcio iônico e, se necessário, administrar gluconato de cálcio $10 \% 1 \mathrm{~mL} / \mathrm{kg}$ em bolus.

O controle da hemorragia envolve a pressão direta sobre o local do sangramento. Se o choque persistir a despeito do controle do sangramento externo e da ressuscitação hídrica, deve-se suspeitar de hemorragia interna. As principais fontes de hemorragia interna que causam choque hipovolêmico em crianças incluem trauma abdominal, trauma torácico e fraturas de ossos longos e de pelve. O trauma craniano isolado raramente causa perda sanguínea suficiente para pro- duzir choque, mas as lacerações de couro cabeludo podem causar sangramento significante e choque hemorrágico em lactentes e crianças jovens. Além disso, outras causas de deterioração cardiopulmonar devem ser descartadas, como a presença de pneumotórax hipertensivo, tamponamento cardíaco ou lesões neurológicas, como lesão medular ou de tronco cerebral, que podem resultar em perda do controle simpático do tônus vascular periférico. ${ }^{2}$

\section{Avaliação da condição neurológica ("Disability")}

A avaliação do estado neurológico em crianças é feita pela utilização da Escala de Coma de Glasgow (ECG) modificada segundo a faixa etária. Esta escala compreende três itens, com pontuação total variando de 3 a 15: abertura ocular (de 1 a 4), melhor resposta verbal (de 1 a 5) e melhor resposta motora (de 1 a 6 ) (Tabela 2).

\section{Tabela 2}

Escala de Coma de Glasgow modificada para crianças

$\begin{array}{cl}\text { Abertura Ocular } \\ 4 & \text { Espontânea } \\ 3 & \text { Ao comando verbal } \\ 2 & \text { À dor } \\ 1 & \text { Nenhuma }\end{array}$

\section{Melhor Resposta Verbal}

\begin{tabular}{clll} 
& $\mathbf{0}-\mathbf{2 3}$ meses & $\mathbf{2 - 5}$ anos & $\mathbf{5}$ anos \\
5 & Sorri, balbucia & Palavras apropriadas & Orientado, conversa \\
4 & Choro apropriado & Palavras inapropriadas & Confuso \\
2 & Choro inapropriado, grito & Choro, gritos & Palavras inapropriadas \\
1 & Gemidos & Gemidos & Sons incompreensíveis \\
Melhor Resposta Motora & Nenhuma & Nenhuma \\
& $<\mathbf{1}$ ano & & \\
6 & & $>\mathbf{1}$ ano & \\
5 & Localiza a dor & Obedece comando & \\
4 & Flexão normal & Localiza a dor & \\
3 & Flexão anormal & Flexão normal & \\
2 & Extensão & Flexão anormal & \\
1 & Nenhuma & Extensão & \\
\hline
\end{tabular}


Ressalta-se que a resposta à dor é componente essencial da função neurológica e deve ser avaliada de maneira apropriada. A capacidade de localizar a dor deve ser avaliada aplicando um estímulo doloroso central, no tronco (entre os mamilos) ou na glabela. $\mathrm{O}$ paciente que é capaz de localizar a dor move as mãos em direção à mão do examinador. A capacidade de retirada do membro frente a um estímulo doloroso deve ser testada estimulando a face medial de cada braço e de cada perna. A resposta de retirada ao estímulo doloroso consiste na abdução de cada membro. Salienta-se que a aplicação do estímulo doloroso nas extremidades dos dedos das mãos ou dos pés pode desencadear movimentos reflexos de flexão e extensão das extremidades. Tais movimentos não correspondem necessariamente à resposta de retirada à dor, mas podem ser apenas reflexos. Outra escala que pode ser usada é a AVDN (Alerta, presença de resposta Verbal, resposta à Dor, Nenhuma resposta). Esta escala, embora menos específica, é mais simples e de realização mais rápida. ${ }^{2}$

\section{Exposição ("Exposure")}

A exposição envolve o exame físico à procura de sinais externos de lesão decorrente de trauma fechado ou penetrante, além da manutenção de ambiente termoneutro para prevenir hipo ou hipertermia. ${ }^{2}$

\section{Avaliação secundária}

A avaliação secundária deve ser realizada após a estabilização inicial do paciente. Para a obtenção de uma história dirigida às circunstâncias do trauma, utiliza-se o símbolo mnemônico AMPLE, perguntando sobre a presença de alergias ("Allergies"), uso de medicações ("Medications"), antecedentes mórbidos, cirurgias anteriores e imunização ("Past medical history"), tempo desde a última refeição e tipo de alimento ingerido, se sólido ou líquido ("Last meal"), e eventos relacionados ao trauma, mecanismos de lesão, tratamentos recebidos na cena do acidente e outros serviços, além do tempo decorrido desde o acidente até a chegada ao serviço de referência ("Events leading to current injury"). ${ }^{2,3}$

Realiza-se, posteriormente, o exame físico detalhado "da cabeça aos pés" à procura de lesões, tomando o cuidado de proteger a coluna vertebral e mantê-la completamente imobilizada durante a manipulação e o transporte do paciente. Deve-se estar atento a sinais de maus-tratos, como a presença de lesões de gravidade desproporcional à história relatada, escoriações, hematomas e equimoses em diferentes estágios de evolução, especialmente em orelhas, pescoço, dorso, coxas e genitais, lesões de queimadura por imersão ("em luva", "em bota", em nádegas ou genitais), marcas de instrumentos na pele (cintos, fios, cigarros, dentes), fraturas múltiplas, particularmente de ossos longos e costelas, hemorragias retinianas ao exame do fundo de olho, sugestivas da síndrome do bebê sacudido, além de sinais de abuso sexual. Nestas situações, o conselho tutelar deve ser notificado para que sejam desencadeadas ações visando à proteção da criança. ${ }^{2-6}$

Após o término do exame físico, traça-se um plano para a realização de estudos diagnósticos, incluindo os exames laboratoriais e de imagem, com base nos achados ao exame físico e na suspeita clínica. Subsequentemente, as prioridades do cuidado são estabelecidas, seguindo a mesma sequência da avaliação inicial, ou seja, as intervenções necessárias à preservação das vias aéreas têm prioridade sobre aquelas que preservam a respiração e a circulação, e assim, sucessivamente. ${ }^{2}$

\section{Particularidades da ressuscitação no trauma crânio-encefálico}

O trauma crânio-encefálico (TCE) é a principal causa de morbi-mortalidade por trauma. De acordo com o momento de sua instalação, as lesões cerebrais são classificadas em primárias e secundárias. As lesões primárias são aquelas que ocorrem no momento do trauma, causadas pela combinação de forças mecânicas que agem sobre o crânio, comprometendo a integridade de neurônios, células endoteliais e glia, e incluem a lesão axonal difusa, a contusão e a laceração. As lesões secundárias são aquelas que ocorrem em intervalo de tempo após o trauma, causadas por distúrbios como hipóxia/ isquemia, hipotensão, convulsões e aumento da pressão intracraniana em decorrência da presença de hematomas, hidrocefalia, ou brain swelling. ${ }^{7}$

O TCE é classificado segundo a gravidade conforme a pontuação da ECG na avaliação inicial, sendo considerado leve, quando o escore inicial da ECG é de 13 a 15, moderado, de 9 a 12, e grave, menor ou igual a 8. Ressalta-se que a avaliação do nível de consciência pela ECG deve ser realizada após estabilização respiratória e hemodinâmica, pois a hipóxia, a hipercapnia e o choque causam rebaixamento do nível de consciência e diminuição da pontuação da ECG., ${ }^{2,7}$ 
A realização de exame de imagem - tomografia computadorizada de crânio - está indicada em todas as crianças com TCE moderado ou grave. Naquelas com TCE leve, a tomografia computadorizada de crânio deve ser feita se houver pelo menos um dos seguintes fatores de risco de lesão intracraniana: ECG menor que 15; sinais focais; evidência de fratura de crânio significante (com diástase, afundamento, fratura aberta ou basilar); perda de consciência no momento do trauma; vômitos persistentes; hematoma em couro cabeludo; alteração do comportamento; coagulopatia. ${ }^{8,9}$

A ressuscitação do paciente com TCE visa garantir a ventilação e a circulação adequadas de modo a prevenir o aparecimento de lesões secundárias. Todos os pacientes com ECG menor ou igual a 8 devem ser intubados pela sequência rápida de intubação. ${ }^{10}$ Este método consiste no uso de agentes farmacológicos com o objetivo de facilitar a intubação e, ao mesmo tempo, reduzir seus efeitos adversos, como a dor, com consequente aumento da pressão intracraniana, além de proteger as vias aéreas contra aspiração de conteúdo gástrico. Os passos da sequência rápida de intubação são os seguintes:

1. Pré-oxigenação com oxigênio a $100 \%$ por 3 a 5 minutos; se o paciente estiver respirando espontaneamente, recomenda-se administrar oxigênio a $100 \%$ por meio de máscara não-reinalante, postergando a ventilação com pressão positiva com bolsa-valva e máscara, que pode causar distensão gástrica e aumento do risco de aspiração do conteúdo do estômago.

\section{Pré-medicação:}

- Atropina 0,01 a 0,02 mg/kg (mínimo 0,1mg; máximo $1 \mathrm{mg}$ ), 1 a 2 minutos antes da intubação; o objetivo é minimizar as respostas desfavoráveis ao estímulo vagal (bradicardia ou assistolia) durante a laringoscopia. O uso de atropina é indicado para todas as crianças menores de 1 ano de idade e para os pacientes que estejam bradicárdicos no momento da intubação.

- Lidocaína 1 a 2 mg/kg, 2 a 5 minutos antes da laringoscopia, para reduzir o aumento da pressão intracraniana que ocorre com a laringoscopia (provavelmente relacionado ao efeito anestésico da lidocaína no sistema nervoso central).

3. Sedação: O tiopental $(3-5 \mathrm{mg} / \mathrm{kg})$ é o agente de escolha no TCE, pois reduz o consumo cerebral de oxigênio e a pressão intracraniana. Em pacientes com instabilidade hemodinâmica, recomenda-se administrar doses baixas de tiopental ( $2 \mathrm{mg} / \mathrm{kg})$. A ketamina é contraindicada em pacientes com TCE, porque aumenta a pressão intracraniana.

4. Manobra de Sellick (pressão sobre a cartilagem cricoide) e ventilação assistida com bolsa-valva e máscara. A pressão cricoide comprime o esôfago, minimizando a entrada de ar no estômago e a possibilidade de refluxo e aspiração do conteúdo gástrico. Além disso, melhora a visualização das cordas vocais, pois desloca a laringe posteriormente.

5. Bloqueio neuromuscular: $\mathrm{O}$ agente de escolha no TCE é o rocurônio $(0,6-1,2 \mathrm{mg} / \mathrm{kg})$. A succinilcolina é agente despolarizante contraindicado no TCE porque aumenta a pressão intracraniana.

6. Intubação traqueal.

Os pacientes com TCE podem apresentar hipertensão intracraniana logo após o trauma ou durante sua evolução, o que contribui significativamente para a morbi-mortalidade causada pelo TCE. Portanto, é fundamental estar atento ao diagnóstico de hipertensão intracraniana, que deve ser tratada prontamente, visando à melhora do desfecho neurológico e da sobrevida do paciente. Os sinais de hipertensão intracraniana em recém-nascidos e lactentes incluem abaulamento e aumento de tensão da fontanela, irritabilidade, choro intenso e recusa alimentar, enquanto que crianças maiores frequentemente apresentam cefaleia, vômitos, diminuição do nível de consciência com piora da pontuação da ECG, anisocoria, pupilas dilatadas e reação pupilar fraca ou ausente à luz. A tríade de Cushing, caracterizada por aumento reflexo da pressão arterial, bradicardia e alteração do ritmo respiratório (bradipneia, apneia e ritmo respiratório irregular ou do tipo Cheyne-Stockes) é um fenômeno tardio que aparece em fases mais avançadas de descompensação da hipertensão intracraniana e constitui situação muito grave, com evolução para a morte, caso a pressão intracraniana não seja reduzida rapidamente com medidas terapêuticas apropriadas.

O tratamento da hipertensão intracraniana consiste em, inicialmente, elevar a cabeceira do leito a $30^{\circ}$, mantendo a cabeça em posição neutra, e realizar hiperventilação para diminuir $\mathrm{PaCO}_{2}$ até $30-35 \mathrm{mmHg}$. Ressalta-se que a hiperventilação prolongada é prejudicial, pois pode levar à isquemia cerebral; entretanto, a hiperventilação aguda pode diminuir substancialmente a pressão intracraniana e salvar a vida do paciente. Durante a hiperventilação, é recomendável que se monitore o $\mathrm{CO}_{2}$ exalado por meio de capnógrafo (lem- 
brar que a $\mathrm{PetCO}_{2}$ é 2 a $3 \mathrm{~mm} \mathrm{Hg}$ menor do que a $\mathrm{PaCO}_{2}$ ). Subsequentemente, caso não haja resposta às medidas iniciais, procede-se à osmoterapia com manitol a $20 \%(0,25-1 \mathrm{~g} / \mathrm{kg} \mathrm{EV}$, em 20 minutos) ou solução salina hipertônica ( $\mathrm{NaCl} 3 \%, 5 \mathrm{~mL} / \mathrm{kg} \mathrm{EV}$, em 30 minutos). A escolha do agente hiperosmolar (manitol ou salina hipertônica) deve levar em conta o estado hemodinâmico; caso o paciente apresente-se com instabilidade cardiovascular, deve-se dar preferência à salina hipertônica em virtude do efeito diurético do manitol. ${ }^{7,11}$

\section{Casos clínicos}

\section{Caso 1}

Criança de 8 anos de idade, vítima de acidente automobilístico, fica presa nas ferragens por cinto de segurança de três pontas. Após ser resgatada pelos bombeiros, é transportada em prancha rígida e com colar cervical a serviço de referência, evoluindo com desconforto respiratório intenso. Ao chegar à sala de trauma apresenta-se inconsciente (Escala de Coma de Glasgow de 6), com cianose generalizada, frequência respiratória de 5 ipm (respirações tipo "gasping"), frequência cardíaca de $150 \mathrm{bpm}$, pressão arterial de 70/40 mm Hg, tempo de enchimento capilar de 4 segundos, pulsos periféricos finos e centrais amplos. A expansibilidade torácica é diminuída à esquerda e observa-se timpanismo à percussão de todo hemitórax esquerdo, com diminuição do murmúrio vesicular do mesmo lado.

\section{Pergunta-se:}

\section{Quais são os diagnósticos?}

Resposta: Politrauma, trauma torácico, pneumotórax hipertensivo à esquerda, insuficiência respiratória aguda grave e choque obstrutivo descompensado.

Comentário: A criança vítima de trauma apresenta, ao exame físico, achados compatíveis com pneumotórax hipertensivo à esquerda (expansibilidade torácica diminuída, timpanismo à percussão e diminuição do murmúrio vesicular), associado a sinais de falência cardiopulmonar (bradipneia com respiração agônica, taquicardia, pulsos finos e tempo de enchimento capilar $>2$ segundos). Portanto, o quadro é compatível com choque obstrutivo. A pressão sistólica mínima para a idade é de $70+(2 \mathrm{x}$ idade em anos $)=86 \mathrm{~mm} \mathrm{Hg}$; assim, o choque é classificado como descompensado.

\section{Qual é o tratamento inicial?}

\section{Consiste no "ABCDE":}

A) Abertura das vias aéreas pela elevação da mandíbula com estabilização simultânea da coluna cervical e aspiração das vias aéreas com sonda grossa e rígida (tipo Yankauer).

B) Ventilação com pressão positiva com bolsa-valva com reservatório de oxigênio e máscara, intubação orotraqueal com estabilização manual simultânea da coluna cervical com cânula número 6 (idade $/ 4+4$ ), fixada em 18 (3 x diâmetro da cânula), realizando a manobra de Sellick (pressão sobre a cartilagem cricoide), e punção torácica de alívio no segundo espaço intercostal esquerdo, linha hemiclavicular, borda superior da terceira costela. Após a intubação, recolocar o colar cervical.

C) Reavaliar. A reavaliação revela que após os procedimentos descritos acima, há melhora imediata das condições respiratórias e hemodinâmicas do paciente, com normalização da saturação de oxigênio, da pressão arterial e da perfusão periférica. Nenhuma intervenção adicional é necessária. Comentário: O tratamento eficaz e sistemático, visando à permeabilidade das vias aéreas e ao alívio do pneumotórax hipertensivo, promove a normalização das condições circulatórias do paciente, sem a necessidade de intervenções posteriores.

D) Avaliar disfunções neurológicas. Observa-se melhora importante do nível de consciência após restabelecimento da oxigenação e da circulação (Escala de Coma de Glasgow 14). Comentário: A avaliação do nível de consciência pela Escala de Coma de Glasgow deve ser realizada em momento de estabilidade respiratória e hemodinâmica, pois a hipóxia, a hipercapnia e o choque causam rebaixamento do nível de consciência e diminuição da pontuação da ECG.

E) Expor totalmente a criança à procura de lesões adicionais e manter a temperatura corporal normal.

\section{Caso 2}

Criança de 5 anos de idade, $20 \mathrm{~kg}$, vítima de acidente automobilístico, é admitida à sala de trauma de serviço de referência com traumatismo crânioencefálico. Ao exame físico, apresenta frequência cardíaca de $60 \mathrm{bpm}$, frequência respiratória de $10 \mathrm{ipm}$, pressão arterial de 140/100 mm Hg, pulsos amplos e simétricos, tempo de enchimento capilar 2 segundos. A saturação de oxigênio em ar ambiente é de $90 \%$. A 
pontuação na escala de coma de Glasgow é de 5 e as pupilas estão anisocóricas (direita maior que esquerda) e com pouca resposta à luz.

\section{Pergunta-se:}

\section{Quais são os diagnósticos?}

Resposta: TCE grave com hipertensão intracraniana.

Comentário: A criança tem pontuação na ECG de 5 e, portanto, o TCE é classificado como grave (ECG menor ou igual a 8). Há sinais clínicos de hipertensão intracraniana grave, incluindo anisocoria e tríade de Cushing (bradipneia, bradicardia e hipertensão arterial sistêmica).

\section{Qual é o tratamento inicial?}

Resposta: Inicialmente, realiza-se o "ABC":

A) Abertura das vias aéreas pela elevação da mandíbula com estabilização simultânea da coluna cervical e aspiração das vias aéreas com sonda grossa e rígida (tipo Yankauer).

B) Como o paciente apresenta TCE grave, deve-se fazer a intubação traqueal, com estabilização manual simultânea da coluna cervical, realizando a sequência rápida de intubação: 1) Pré-oxigenação com oxigênio a $100 \%$ por 3 minutos com bolsavalva e máscara; 2) Pré-medicação - atropina 0,2 mg; 3) Sedação com tiopental (100 mg); 4) Manobra de Sellick (pressão sobre a cartilagem cricoide); 5) Bloqueio neuromuscular com rocurônio (12 - 24 $\mathrm{mg})$; 6) Intubação traqueal.

Comentário: É extremamente importante que se realize a sequência rápida de intubação neste caso, pois o paciente já apresenta sinais clínicos de descompensação da hipertensão intracraniana, que poderia se agravar durante o procedimento, caso o paciente sentisse dor ou apresentasse movimentação espontânea ou tosse. A atropina neste caso está indicada porque o paciente se apresenta bradicárdico.

C) Não há sinais de choque.

Comentário: A hipertensão arterial neste caso é reflexa, por aumento da pressão intracraniana, e visa manter a pressão de perfusão cerebral adequada (pressão de perfusão cerebral $=$ pressão arterial média pressão intracraniana). Nesta situação, o uso de antihipertensivo é contraindicado, pois pode causar isquemia cerebral. A pressão arterial sistêmica retornará aos níveis normais com o controle da hipertensão intracraniana.

- Tratamento da hipertensão intracraniana: A hipertensão intracraniana constitui uma emergência e deve ser tratada prontamente, ainda na sala de trauma. Inicialmente, eleva-se a cabeceira do leito a $30^{\circ}$, mantendo a cabeça em posição neutra (evitando lateralização do pescoço), para facilitar o retorno venoso. Faz-se então hiperventilação manual (com bolsa-valva ou aparelho de ventilação mecânica), diminuindo a $\mathrm{PaCO}_{2}$ até 30-35 mm $\mathrm{Hg}$. Caso não haja resposta, administra-se $\mathrm{NaCl} 3 \% 100 \mathrm{~mL}(\mathrm{NaCl}$ $20 \% 15 \mathrm{~mL}$ + água destilada $85 \mathrm{~mL}$ ) EV em 30 minutos ou manitol $20 \% 25 \mathrm{~mL}$ ( $5 \mathrm{~g}$ ou $0,25 \mathrm{~g} /$ $\mathrm{kg})$ EV em 20 minutos.

- Após melhora do quadro, caracterizada por normalização dos sinais vitais e das pupilas, encaminha-se o paciente para realização de tomografia computadorizada de crânio.

\section{ABSTRACT}

This paper discusses the initial assessment and systematic management of the pediatric trauma victim, as well as the peculiarities of resuscitation of head injured children.

Keywords: Multiple Trauma. Primary Survey. Secondary Survey. Head Injury.

\section{Referências Bibliográficas}

1. Datasus. Ministério da Saúde, Brasil, 2002ª . Disponível em: http://tabnet.datasus.gov.br
2. American Heart Association. PALS - Pediatric Advanced Life Support - Provider Manual, 2002.

3. Wetzel RC, Burns C. Multiple trauma in children: critical care overview. Crit Care Med 2002; 30(Suppl.): S468-77. 
4. McDonald KC. Child abuse: approach and management. Am Fam Physician 2007; 75:221-8.

5. Newton AW, Vandeven AM. Child abuse and neglect: a worldwide concern. Curr Opin Pediatr 2010; 22:226-33.

6. Herman BE, Makoroff KL, Corneli HM. Abusive head trauma. Pediatr Emer Care 2011; 27:65-9.

7. Mazzola CA, Adelson D. Critical care management of head trauma in children. Crit Care Med 2002; 30(Suppl.):S393-401.

8. Dunning J, Batchelor J, Stratford-Smith P, Teece S, Browne J, Sharpin C, et al. A meta-analysis of variables that predict significant intracranial injury in minor head trauma. Arch Dis Child 2004; 89:653-9.
9. Oman JA, Cooper RJ, Holmes JF, Viccellio P, Nyce A, Ross SE, et al. Performance of a decision rule to predict need for computed tomography among children with blunt head trauma Pediatrics 2006; 117: e238-46.

10. Zelicof-Paul A, Smith-Lokridge A, Schnadower D, Tyler S, Levin S, Roskind C, Dayan P. Controversies in rapid sequence intubation in children. Current Opinion in Pediatrics 2005; 17:355-62.

11. Timmons SD. Current trends in neurotrauma care. Crit Care Med 2010; 38(Suppl.): S431-44. 